\section{RHEOLOGICAL CHARACTERISTIC OF VOLCANIC CLAY AND IMPLICATION TO ITS LONG-TERM STRENGTH AND TIME DEPENDENT BEHAVIOR}

Tonny Lesmana Baskaria,b*, Zufialdi Zakariaa, Nana Sulaksanaa, Budi Muljanaa

aFaculty of Geological Engineering, Universitas Padjadjaran, Jatinangor, Sumedang, 45363, Indonesia bGeoACE, Bandung, 40286, Indonesia
Article history

Received

3 May 2021

Received in revised form

9 September 2021

Accepted

9 September 2021

Published Online

21 February 2022

${ }^{*}$ Corresponding author tonny20001@mail.unpad.ac.id
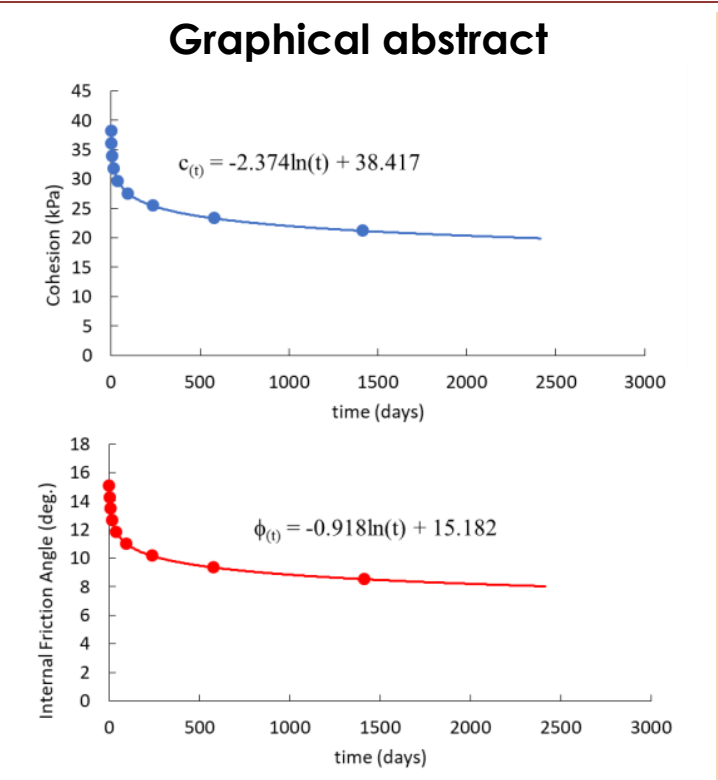

\section{Abstract}

As a natural phenomenon, land movement does not occur suddenly, but it is a long-term phenomenon in the form of un-recoverable low rates deformation caused by constant stress on a slope body and known as creep. Therefore, it is very important to understand the rheological characteristics of the soil under constant stress and implication to its longterm strength and time dependent behavior of a soil mass. The laboratory shear creep tests were carried out on 15 undisturbed volcanic clay samples taken from the southern slopes of Lembang Village, Cililin, West Java, Indonesia. The tests were carried out by applying a constant shear stress level of $50 \%-95 \%$ from the peak shear strength. The results show that the level of constant shear stress will affect to the rheological characteristics of the soil samples. The higher level of shear stress, the shorter failure time. Based on the shear creep tests, the rheological model was established, the failure time of the soil samples were estimated and the long-term strength equation was obtained. The long-term shear strength of the volcanic clay is decrease $52.38 \%$ from the peak shear strength and achieved after 925 days $( \pm 31$ months). The cohesion (c) and internal friction angle $(\phi)$ decrease from $41.548 \mathrm{kPa}$ and $17.051^{\circ}$ become $21.188 \mathrm{kPa}$ and $9.129^{\circ}$, respectively. The shear creep test also shows that the soil shear strength parameters ( $c$ and $\phi$ ) are a function of time.

Keywords: Rheology, Long-term strength, Time dependent behavior, Constant stress, Shear creep

(c) 2022 Penerbit UTM Press. All rights reserved

\subsection{INTRODUCTION}

Land movement that occurs in densely populated areas is a serious problem and needs immediate handling because it involves the safety of humans, property and the infrastructure underneath. There needs to be the same perspective among stakeholders such as government, scientists, employers and communities regarding efforts to reduce losses incurred, both property and human lives due to land movement [1]. As a natural phenomenon, land movement does not occur suddenly but is a long-term phenomenon in the form of un-recoverable low rates deformation caused by constant stress on a slope body and known as creep. Creep is the slow movement of soil/rock due to the 
reduction of internal shear stress on a slope body causes long-term deformation but is not sufficient to trigger landslides [2].

Time-dependent shear strength reduction caused by constant stress is usually ignored and often neglected. This is because the long-term deformation usually has a small degree with a very low speed and difficult to observe with the naked eye [3]. However, there are many situations where the time-dependent behavior of soil/rock must be considered [4,5]. Constant stress acting on the slope body does not have a significant effect on the current slope stability but will cause long-term deformation which will have an important role in the long-term slope stability [6]. It is very important to formulate the effect of the constant stress acting on the slope body in relation to the shear strength reduction of the soil mass as a time function so that we can estimate the long-term strength of the soil mass and its time-dependent behavior.

Several studies have been conducted to understand the geo-material rheological characteristics. Baskari [7] conducted a shear creep test on claystone samples taken from a coal mine site in East Kalimantan, Indonesia and determined the magnitude of the long-term reduction in rock shear strength. Luo and Chen [8] observed deformation rate in relation to time through triaxial creep test on the soft soil of Nansha, Guangzou China. Fan et al. [9] conducted research on the constitutive model of mudstone from Badong Formation through a shear creep test and concluded that the Burgers and Nishihara rheological models could describe the rheological characteristics fairly well. Wang et al. [10] conducted a rheological modeling experiment of Beijing soft clay through multi-stage triaxial creep and stated that deformation on soft clay has obvious time effects and non-linear characteristics. Ma et al. [11] conducted a rheological model study of soft layers in the Maokou Formation and prove that the moisture content has a significant effect on the long-term strength of the soft layer. Yang et al. [5] conducted a multistage in-situ creep test on a fault zone at Dagangshan Hydropower Station, China and suggested a visco-elastic-plastic softening model for use in the rheological model. Liu et al. [12] conducted a study of time-dependent failure mechanisms in rocks with numerical modeling in relation to slope stability. Most of these studies discussed the rheological behavior of soil/rock and have not discussed the failure time prediction of soil/rock samples based on the rheological model established from the creep test.

Saito and Uezawa [13] conducted a study to predict the failure time of a slope based on field observations and stated that the failure time of a slope is closely related to the strain rate. Fukuzono [14] conducted a study to predict the failure time of a slope by using the Inverse Number of Velocity of Surface Displacement. Adriansyah [15] monitoring slope movement in the Batu Hijau mine, West Nusa
Tenggara, Indonesia to predict the slope failure time and proposed an equation to estimate the slope failure time. Li et al. [16] conducted in-situ monitoring to understand the deformation mechanism of landslide in relation to water level fluctuations in the Three Gorges reservoir area and used H-K rheological constitutive model to landslide deformation. Monitoring data used in this research is data collected from September 2004 to August 2010. However, unfortunately, monitoring the slope movement in the field takes a very long time and relatively costly. This paper will discuss how to formulate the rheological characteristics of soil due to constant stresses and estimate the failure time with the rheological model obtained from the laboratory shear creep test so that the long-term strength of the soil and its time-dependent behavior can be determined.

The research site is located at the southern slope of Lembang Village, Cililin, West Java, Indonesia and known as a landslide-prone area and categorized as medium - high soil movement vulnerability zone [17].

\subsection{METHODOLOGY}

\subsection{Laboratory Shear Creep Test}

The standard direct shear (quick test) test was carried out and the result was used as a reference for the application of shear stress levels in the shear creep test. Normal load of $10 \mathrm{kPa}, 20 \mathrm{kPa}$ and $30 \mathrm{kPa}$ were applied in the standard direct shear test. The soil specimens have dimensions of $6.25 \mathrm{~cm}$ in diameter and a thickness of $2.10 \mathrm{~cm}$.

The shear creep test was carried out by applying normal stress and constant shear stress until the material failure for a certain time or until secondary creep is achieved. Fifteen undisturbed volcanic clay samples were taken from the research area at a depth of 2.5 to 3.0 meters using a hand auger. The tests observation was set for \pm 7 days, but it can be finished earlier if the soil samples failure. The longterm shear strength is determined by describing the curve of the shear stress level with respect to the failure time [18, 19] (see Figure 1).

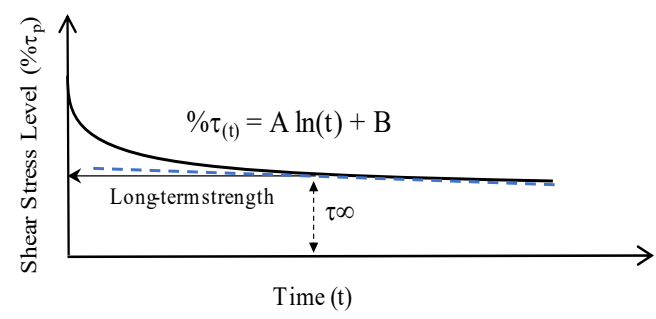

Figure 1 Long-term Strength Curve [18,19] 


\subsection{Rheological Model}

Rheology is a branch of science that studies the flow phenomenon and deformation of a material which describes the relationship between force, deformation and time [20]. In general, it deals with materials that are is a visco-elastic complex that shows the response of solid and liquid materials to force, deformation and time. The visco-elastic rheological model consists of two (2) basic mechanics, namely: Spring (Hookean) and Dashpot (Newtonian). Several rheological models can be used to describe the mechanical behavior of a material. One that is widely used in rheological modelling is the Burgers rheological model (Figure 2).

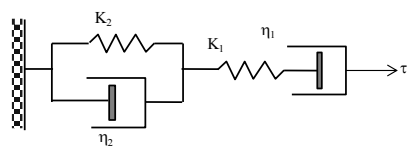

Figure 2 Burgers Rheological Model

Burgers rheological model is good and preferable for many practical purposes in describing the rheological characteristics of a material [9,21]. Baskari [7] conducted a study on the creeping behavior using Burgers rheological model approach with satisfactory results. Yang et al. [5] stated that the Burgers rheological model can describe the instantaneous deformation stage, primary stage and secondary stage fairly well; but cannot describe the tertiary creep curves where the soil samples failure.

The equation for the Burgers rheological model with shear stress is represented by:

$\varepsilon_{(t)}=\frac{\tau}{K_{1}}+\frac{\tau}{K_{2}}\left(1-e^{-\frac{K_{2}}{\eta_{2}} t}\right)+\frac{\tau}{\eta_{1}} t$

Where $\varepsilon_{(t)}$ is deformation with respect to time $t ; \tau$ is constant shear stress; $\eta_{1}$ is the viscous flow rate; $\eta_{2}$ is the delayed elastic rate; $K_{1}$ is the shear stiffness; $K_{2}$ is the delayed shear stiffness.

Rheological constants in Equation (1) determined based on the method proposed by [4]:

$\eta_{1}=\frac{\tau \cdot t}{\left(\varepsilon_{t}-\varepsilon_{o}\right)} \quad K_{2}=\frac{\tau}{10^{\log q}}$

$K_{1}=\frac{\tau}{u_{o}-\frac{\tau}{K_{2}}} \quad \eta_{2}=\frac{k_{2}\left(t_{1}-t_{2}\right)}{2.3\left(\log q_{1}-\log q_{2}\right)}$

Where $\varepsilon_{o}$ initial displacements, $q$ is the distance between the points on the liner regression against the creep curve, $U_{0}$ is the displacement at $t_{0}, q_{1}$ is the linear regression distance at $t_{1}$ and $q_{2}$ is the linear regression distance at $t_{2}$.

\subsection{Creep Characteristic}

Creep is the tendency of a solid material to move slowly and deformed permanently due to constant stress acting continuously for a long period of time where the magnitude of constant stress is smaller than its peak strength [18, 19].

Figure 3 is the creep curve of a material that is subjected to stress. Elastic deformation occurs immediately after constant shear stress is applied and followed by primary creep. At this stage, the sample will return to its normal state if the working stress is eliminated (PQR). Secondary creep is indicated by deformation at a constant rate and when the stress is stopped, permanent deformation (STU) has occurred. In tertiary creep, the speed of elastic deformation will increase progressively $\left(\varepsilon_{\mathrm{pr}}\right)$ until the sample failure. The creep deformation formulated as:

$\varepsilon_{(t)}=\varepsilon_{0}+\left.\varepsilon_{1}\right|_{0} ^{t_{s s}}+\left.\varepsilon_{2}\right|_{t_{s s}} ^{t_{p r}}+\left.\varepsilon_{3}\right|_{t_{p r}} ^{t_{f a i l}}$

Where $\varepsilon_{(t)}$ is total deformation as a function of time; $\varepsilon_{0}$ is instantaneous deformation; $\varepsilon_{1}$ is the primary creep; $\varepsilon_{2}$ is the secondary creep; $\varepsilon_{3}$ is the tertiary creep.

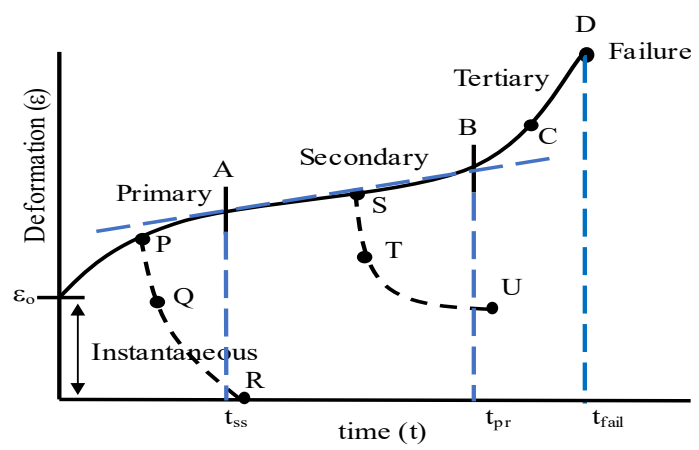

Figure 3 Creep Curve $[4,19,20,21]$

In many cases, to get the four stages of the creep $\left(\varepsilon_{0}, \varepsilon_{1}, \varepsilon_{2}\right.$ and $\left.\varepsilon_{3}\right)$ in laboratory testing will take a long time (weeks to months or even years) while for research purposes a shorter time is required. Therefore, tertiary creep $\left(\varepsilon_{3}\right)$ is commonly excluded from the analysis [22,23] and Equation (3) can be rewritten as:

$\varepsilon_{(t)}=\varepsilon_{0}+\varepsilon_{1}+\varepsilon_{2}$

The creep proses divided into 2: non-attenuating creep and attenuating creep [18,19] (see Figure 4). Non-attenuating creep is the creep in which the $\varepsilon_{o}, \varepsilon_{l}$, $\varepsilon_{2}$ and $\varepsilon_{3} s$ achieved. Non-attenuating creep occurs when the level of shear stress is large enough to cause material failure. At low levels of shear stress, the $\varepsilon$ is usually not achieved and called attenuating creep. In this condition, the secondary creep rate appears stable and shows long-lasting creep. The maximum deformation during the test is defined as the ultimate deformation

The strength limit of the material is the stress when the material begins to collapse or when the deformation rate starts to increase progressively $\left(\varepsilon_{\mathrm{pr}}\right)$. 
In this case $\varepsilon_{\text {ult }} \approx \varepsilon_{\text {prr. }}$. Failure deformation (Efail) is the stress where the deformation is up to $50 \%$ greater than progressive deformation $\left(\varepsilon_{\mathrm{pr}}\right)[18,19]$ :

$$
\varepsilon_{\mathrm{fail}}=1.5 \varepsilon_{\mathrm{pr}}
$$
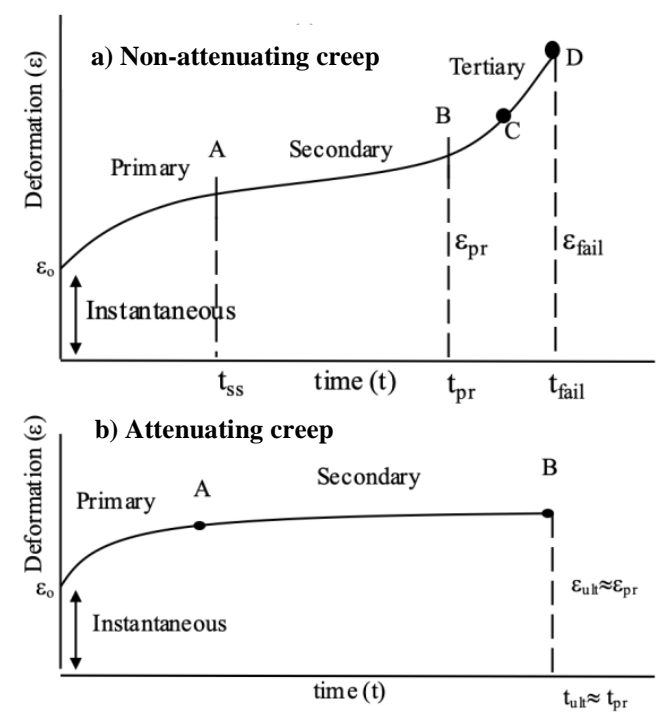

Figure 4 Deformation and Time on Creep [18, 19]

\subsection{RESULTS AND DISCUSSION}

\subsection{Geological Setting}

Based on the Regional Geological Map of the Cianjur Quadrangle $[24,25,26]$, rock units in the research area and its surroundings consisting of (Figure 5):

\section{a. Alluvial (Qa)}

Alluvial (Qa) unit, composed of clay, silt, sand and gravel. Mainly river sediments and flood plains deposits, including talus around research area. This unit has age relatively Quaternary.

\section{b. Lake Deposit (QI)}

Tuffaceous clays, tuffaceous sand, tuffaceous conglomerates. Forming horizontal bedding in several places. Contains limestone concretions, plant remains, freshwater molluscs and bones of vertebrates. This unit has age relatively Quaternary.

\section{c. Andesite}

Porphyry andesite has grey colour when fresh and dark grey colour when weathered, porphyritic, inequigranular fabric, subhedral crystal shaped, hypidiomorf, mesocratic. Primary structure are massive, columnar jointing and sheeting joints. This unit intruded $\mathrm{Pv}$ with age relative Pliocene.

\section{d. Volcanic Rock (Pv)}

This unit consisting of Tuff and pyroclastic fall monomic Breccia. Tuff, unconsolidated, brownish to dark grey, grainsize from tuff (dominant) until lapilli, but some reach the size of bomb. The pyroclastic fall monomic Breccia has grey to brownish grey, grain size 2 - $80 \mathrm{~cm}$, angular - sub-angular, open fabric, poorly sorted. The components are porphyry andesite and crystalline tuff matrix. The age of this unit is Miocene. Fifteen undisturbed volcanic clay samples have been taken from this unit.

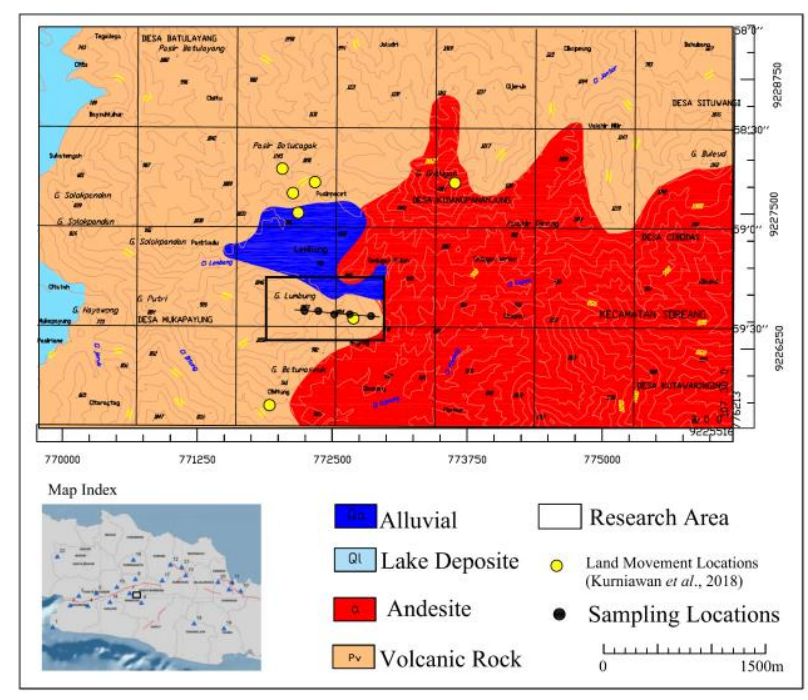

Figure 5 Geological Map of Cililin Area [24, 25, 26]

Geomorphologically, the research location and its surroundings are composed of hills with a very steep slope with elevation from 650 up to $1400 \mathrm{~m}$. Flow patterns that develop are radially and subdendritic. No-fault was observed in this area. There are two active faults at the north part of the research area which are Lembang Fault and Cimadiri Fault. The distances of the active fault are $25 \mathrm{~km}$ and 30 $\mathrm{km}$, respectively, from the research area.

Figure 5 and Table 1 show that the areas with high potential for landslides are located at the area composed of Mio-Pliocene volcanic products and andesitic intrusion and andesitic lava [24, 25, 26].

To determine the mineralogy characteristics of volcanic clay in the research area, XRD and Petrography analyses were carried out. The result of the XRD and Petrography is shown in Figure 6. 


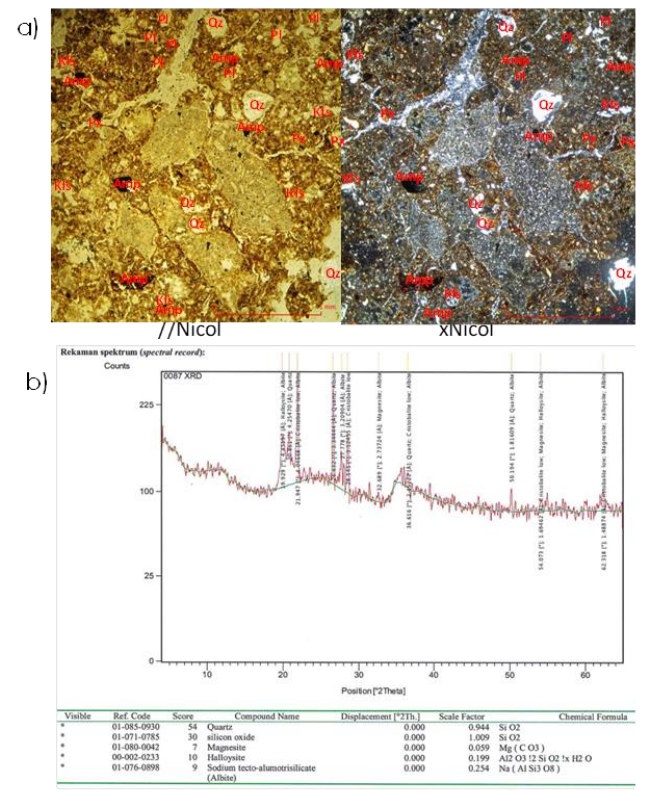

Figure 6 Petrographic (a) and XRD Pattern (b)

Table 1 Classification of Landslide Potential in Research Area [25]

\begin{tabular}{|c|c|c|c|c|}
\hline $\begin{array}{l}\text { Slope } \\
\text { Deg. }\end{array}$ & Lithology & Land Use & Morphometry & $\begin{array}{l}\text { Landslide } \\
\text { Potential }\end{array}$ \\
\hline$>50^{\circ}$ & $\begin{array}{l}\text { Miocene-Pliocene volcanic } \\
\text { materials, andesite rock }\end{array}$ & $\begin{array}{l}\text { Farm, Paddy Field } \\
\text { and Residences }\end{array}$ & $\begin{array}{l}\text { Medium-high im-permeability, } \\
\text { weathering and erosion }\end{array}$ & $\begin{array}{l}\text { High } \\
\text { Potential }\end{array}$ \\
\hline $14^{\circ}-50^{\circ}$ & $\begin{array}{l}\text { Miocene-Pliocene volcanic } \\
\text { materials, andesite rock }\end{array}$ & $\begin{array}{l}\text { Farm, Paddy Field } \\
\text { and Residences }\end{array}$ & $\begin{array}{l}\text { Low - Medium im-permeability, } \\
\text { weathering and erosion }\end{array}$ & $\begin{array}{l}\text { Medium } \\
\text { Potential }\end{array}$ \\
\hline $5^{\circ}-14^{\circ}$ & $\begin{array}{l}\text { Miocene-Pliocene volcanic } \\
\text { materials, Quaternary deposit }\end{array}$ & Farm and Residences & $\begin{array}{l}\text { Low - Medium im-permeability, } \\
\text { weathering and erosion }\end{array}$ & $\begin{array}{l}\text { Low } \\
\text { Potential }\end{array}$ \\
\hline $0^{\circ}-5^{\circ}$ & $\begin{array}{l}\text { Miocene-Pliocene volcanic } \\
\text { materials, Quaternary deposit }\end{array}$ & $\begin{array}{l}\text { Paddy Field } \\
\text { Residences }\end{array}$ & $\begin{array}{l}\text { Low - Medium im-permeability, } \\
\text { weathering and erosion }\end{array}$ & None \\
\hline
\end{tabular}

From the XRD results, the clay minerals contained in the volcanic clay consist of halloysite in which is classified as Sensitive Clay [27]. At Taurangga Region New Zealand, halloysite as a result of weathering from volcanic material plays a significant role in the major landslide [28]. Meanwhile, a thin section shows medium texture and composed of plagioclase, k-feldspar, quartz and amphibole as crystal fragments. Igneous and tuff fragment as a lithic fragment. Glass fragments. Clay mineral, volcanic glass and iron oxide as a matrix. Opaque minerals as secondary minerals altered from pyroxene and amphibole.

\subsection{Physical Properties and Direct Shear Test}

Physical properties and direct shear tests were conducted on the undisturbed soil samples. The result of the physical and mechanical properties of the soil sample is presented in Table 2.
Table 2 Soil Mechanics Laboratory Test

\begin{tabular}{llll}
\hline Laboratory test & Symbol & Unit & Value \\
\hline Index Properties & & & \\
Specific Gravity & $\mathrm{Sg}$ & $\mathrm{kN} / \mathrm{m}^{3}$ & 2.65 \\
Bulk density & $\gamma \mathrm{n}$ & $\mathrm{kN} / \mathrm{m}^{3}$ & 17.13 \\
Dry density & $\gamma \mathrm{dry}$ & $\mathrm{kN} / \mathrm{m}^{3}$ & 11.87 \\
\hline Atterberg limit & & & \\
Liquid limit & $\mathrm{LL}$ & $\%$ & 43.01 \\
Plastic limit & $\mathrm{PL}$ & $\%$ & 28.87 \\
Plastic index & $\mathrm{PI}$ & $\%$ & 14.13 \\
Soil class & $\mathrm{Class}$ & & $\mathrm{CL}$ \\
\hline Grainsize distribution & & & \\
Clay & & $\%$ & 73.83 \\
Silt & & $\%$ & 24.42 \\
Sand & & $\%$ & 1.75 \\
\hline Direct shear test & \multicolumn{3}{|}{} \\
Cohesion & $\mathrm{C}$ & $\mathrm{kPa}$ & 41.548 \\
Internal friction angle & $\circ$ & $\mathrm{Deg}$. & 17.05 \\
\hline
\end{tabular}




\subsection{Shear Creep Test}

The level of shear stress $\left(\% \tau_{p}\right)$ applied to the shear creep test ranges from $50 \%$ to $95 \%$ of the peak shear strength $\left(\tau_{p}\right)$. Figure 7 shows the creep curve from the laboratory shear creep test.

From Figure 7 it can be seen that non-attenuating creep occurs at CR1.1, CR1.2, CR2.1, CR2.2 and CR3.3, where the shear stress levels between $80 \%$ and $95 \%$, while attenuating creep occur at shear stress level less than $75 \%$.

In non-attenuating creep, the creep tests show elasto-viscoplastic behavior where the $\varepsilon_{0}, \varepsilon_{1}, \varepsilon_{2}$ and $\xi_{3}$ which ended in failure were achieved. The failure time ranges from 29 minutes up to 6 days depend the stress level applied. The higher level of shear stress, the shorter the failure time.

In attenuating creep, the creep curves only show $\varepsilon_{0}, \varepsilon_{1}$ and $\varepsilon_{2}$ while $\varepsilon_{3}$ were not achieved along 7 days of creep test observation. Under these conditions, the rate of secondary creep appears to be stable and tends to show long-lasting creeps [21]. This occurs due to the low level of shear stress applied on the test so that the test samples show a visco-elastic behavior. Based on the result of the shear creep tests, it can be concluded that the level of shear stress applied during the shear creep test will affect to the rheological characteristics of the soil samples.
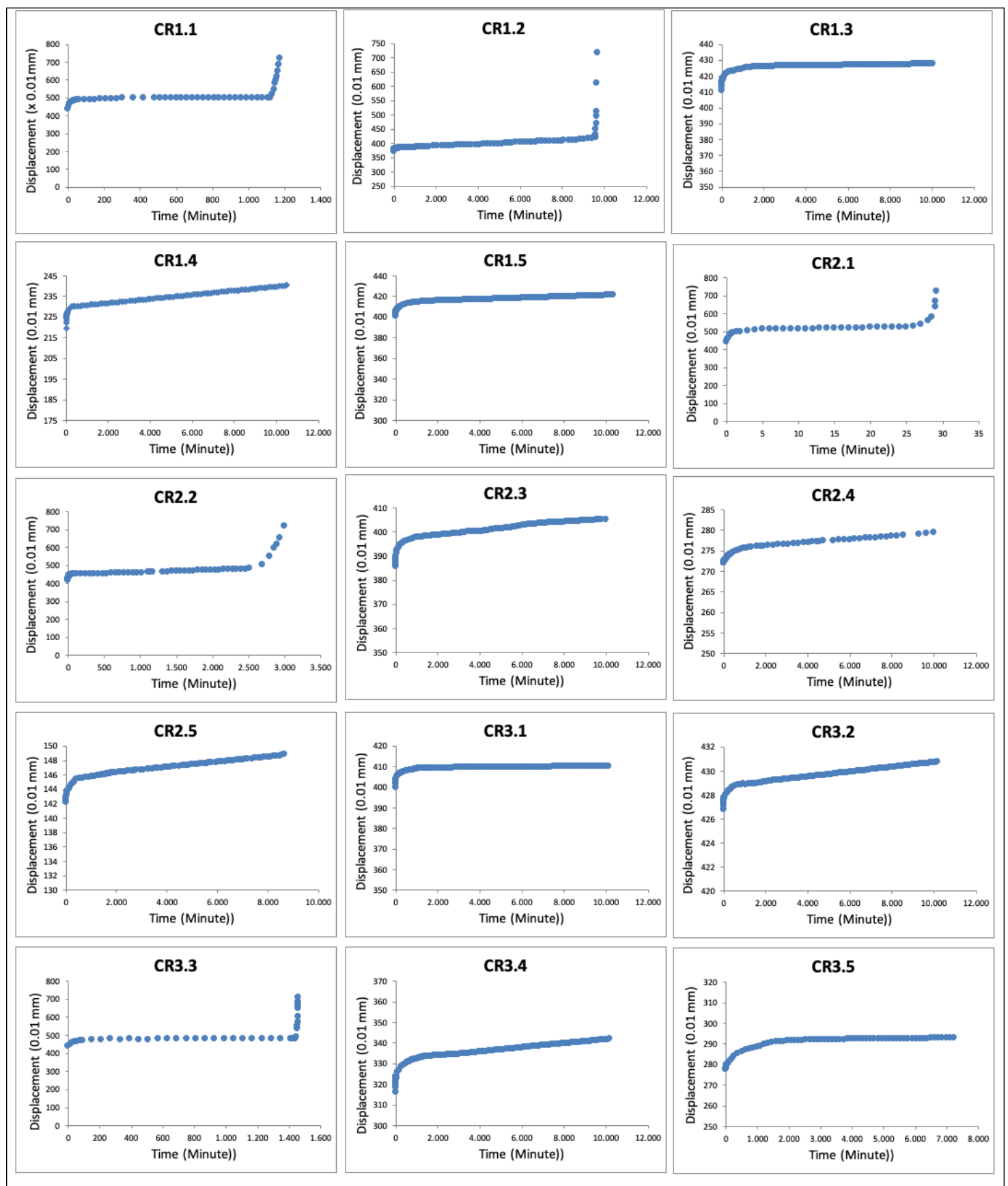

Figure 7 Creep Curve 


\subsection{Rheological Model}

In non-attenuating creep, the time at which the sample failure is defined as the failure time of the material. Whereas in attenuating creep, the maximum deformation observed when the test was stopped (on the $7^{\text {th }}$ days) was recorded. Meanwhile, the strength limit ( $\left.\varepsilon_{\mathrm{pr}}\right)$ was determined refer to Equation (5).

Goldstein and Ter-Stepanian [29] conducted a triaxial creep test on clays samples and states that when the conditions of the samples and the test are similar, the samples with different stress will failure at a different time depend on the stress level applied, but magnitude deformation will be relatively the same. This is consistent with the direct shear tests in this research which shows the magnitude of failure deformation has relatively same, ranges from 7.2 - 7.7 $\mathrm{mm}$ with an average of $7.4 \mathrm{~mm}$. If this is the case, then the failure time of a soil material can be estimated based on the rheological model established from the shear creep test. The strength limit $\left(\varepsilon_{\mathrm{pr}}\right)$ can be determined according to Equation (5): $7.40 / 1.5=4.91 \mathrm{~mm}$.

The magnitude progressive deformation $\left(\varepsilon_{\mathrm{pr}}\right)$ refer to Equation (4) where creep deformation is considered as the sum of $\varepsilon_{0}, \varepsilon_{1}$ and $\varepsilon_{2}$ while $\varepsilon_{3}$ was excluded [22,23]. Equation (4) fits with the Burgers rheological model used in this research where the Burgers model can describe the visco-elastic model which consists of $\varepsilon_{0}, \varepsilon_{1}$ and $\varepsilon_{2}$ fairly well, but does not describe the presence of $\varepsilon_{3}$ [5]. The estimation time when $\varepsilon_{\mathrm{pr}}$ is reached was calculated by the Burgers rheological model established in Table 3 for each soil sample.

\subsection{Long-term Shear Strength}

Long-term shear strength is the relationship between the shear stress level and the time achieved when the soil begins to failure $\left(t_{\text {spr }}\right)$. Figure 8 is the long-term shear strength curve which is determined by plotting the shear stress level in correlation to time ( $\left.\mathrm{t}_{\mathrm{pr}}\right)[18$, 19].

Table 3 Burgers Rheological Model and $\dagger_{(e p r)}$

\begin{tabular}{|c|c|c|c|c|c|}
\hline Sample & $\begin{array}{l}\text { Normal } \\
\text { Stress } \\
\sigma_{\mathrm{n}} \\
(\mathrm{kPa})\end{array}$ & $\begin{array}{l}\text { Shear } \\
\text { Stress } \\
\tau_{p} \\
(\mathrm{kPa})\end{array}$ & $\begin{array}{l}\text { Shear } \\
\text { Stress } \\
\text { Level } \\
\left(\% \tau_{p}\right)\end{array}$ & $\begin{array}{c}\text { Burgers Rheology } \\
\varepsilon_{(t)}=\frac{\tau}{K_{1}}+\frac{\tau}{\eta_{1}} t+\frac{\tau}{K_{2}}\left(1-e^{-\frac{K_{2} t}{\eta_{2}}}\right)\end{array}$ & $\begin{array}{r}t_{\left(\varepsilon_{p r}\right)} \\
\text { Minutes }\end{array}$ \\
\hline CR1.1 & & & 92.29 & $\varepsilon_{(t)}=4.414+(1.00 E-04) t+4.684 E-01\left(1-e^{(-6.601 E-02) t}\right)$ & 1,175 \\
\hline CR 1.2 & & & 83.06 & $\varepsilon_{(t)}=3.743+(4.00 E-05) t+8.482 E-02\left(1-e^{(-1.426 E-02) t}\right)$ & 9,681 \\
\hline CR 1.3 & 10 & 44.18 & 62.76 & $\varepsilon_{(t)}=4.176+(2.00 E-06) t+7.876 E-02\left(1-e^{(-2.300 E-03) t}\right)$ & 328,550 \\
\hline CR 1.4 & & & 60.91 & $\varepsilon_{(t)}=2.242+(1.00 E-05) t+5.621 E-02\left(1-e^{(-1.289 E-02) t}\right)$ & 261,200 \\
\hline CR 1.5 & & & 72.35 & $\varepsilon_{(t)}=4.032+(7.00 E-06) t+1.101 E-01\left(1-e^{(-4.370 E-03) t}\right)$ & 109,350 \\
\hline CR2.1 & & & 95.00 & $\varepsilon_{(t)}=4.376+(1.18 E-02) t+5.906 E-01\left(1-e^{(-2.239 E-00) t}\right)$ & 29 \\
\hline CR2.2 & & & 88.22 & $\varepsilon_{(t)}=4.298+(1.00 E-04) t+2.084 E-01\left(1-e^{(-4.209 E-02) t}\right)$ & 2,995 \\
\hline CR2.3 & 20 & 48.07 & 67.86 & $\varepsilon_{(t)}=3.888+(1.00 E-05) t+7.869 E-02\left(1-e^{(-4.140 E-03) t}\right)$ & 94,403 \\
\hline CR2.4 & & & 57.68 & $\varepsilon_{(t)}=2.718+(4.00 E-06) t+3.526 E-02\left(1-e^{(-2.760 E-03) t}\right)$ & 539,353 \\
\hline CR2.5 & & & 52.59 & $\varepsilon_{(t)}=1.425+(4.00 E-06) t+2.730 E-02\left(1-e^{(-5.520 E-03) t}\right)$ & 864,505 \\
\hline CR3.1 & & & 52.15 & $\varepsilon_{(t)}=4.043+(8.00 E-07) t+4.985 E-02\left(1-e^{(-2.300 E-03) t}\right)$ & $1,023,140$ \\
\hline CR3.2 & & & 58.66 & $\varepsilon_{(t)}=4.273+(2.00 E-06) t+1.343 E-02\left(1-e^{(-4.8308 E-03) t}\right)$ & 312,200 \\
\hline CR3.3 & 30 & 50.04 & 84.74 & $\varepsilon_{(t)}=4.377+(5.00 E-05) t+3.665 E-01\left(1-e^{(-2.254 E-02) t}\right)$ & 1,459 \\
\hline CR3.4 & & & 61.92 & $\varepsilon_{(t)}=3.223+(1.00 E-05) t+9.789 E-02\left(1-e^{(-2.760 E-03) t}\right)$ & 159,100 \\
\hline CR3.5 & & & 53.78 & $\varepsilon_{(t)}=2.776+(2.00 E-06) t+1.387 E-01\left(1-e^{(-1.610 E-03) t}\right)$ & 997,610 \\
\hline
\end{tabular}

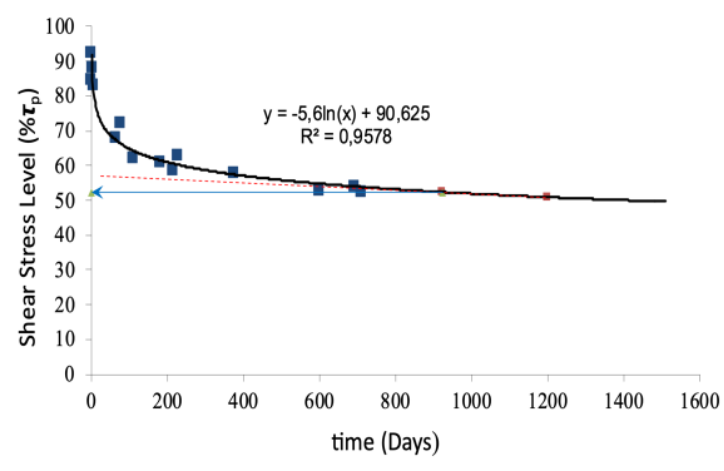

Figure 8 Long-term Shear Strength Curve
Figure 8 shows that the long-term shear strength of Cililin Volcanic Clay decreased up to $52.38 \%$ from its peak shear strength after 925 days ( \pm 31 months) and is represented by Equation (6). The soil parameter cohesion (c) and internal friction angle $(\phi)$ decrease from $41.548 \mathrm{kPa}$ and $17.051^{\circ}$ become $21.188 \mathrm{kPa}$ and 9.1290 , respectively. Research that has been done on several soils and rock materials shows that the longterm strength reduction in the creep test ranges from $50 \%-80 \%[3,7,19]$. This shows that constant stress has significant effects on the long-term strength of the soil mass.

$\% \tau=-5.60 \ln (t)+90.625$ 


\subsection{Time-dependent Behavior of Soil Parameter}

Equation (6) was used to determine the reduction in soil shear strength parameter (c and $\phi$ ) as a function of time. The results of the calculations are tabulated in Table 4.

Table 4 Time-dependent of Volcanic Clay Parameter

\begin{tabular}{llll}
\hline $\begin{array}{l}\text { Stress } \\
\text { Level } \\
\left(\% \tau_{\mathrm{p}}\right)\end{array}$ & $\begin{array}{l}\text { Failure time } \\
\text { (days) } \\
\text { (Equation 6) }\end{array}$ & $\begin{array}{l}\mathrm{C}_{(\mathbf{(})} \\
\mathbf{( k P a )}\end{array}$ & $\begin{array}{l}\boldsymbol{\phi}(\mathbf{(}) \\
(\mathbf{d e g} .)\end{array}$ \\
\hline 50 & 1414.41 & 21.19 & 8.49 \\
55 & 579.18 & 23.32 & 9.34 \\
60 & 237.16 & 25.44 & 10.17 \\
65 & 97.11 & 27.55 & 10.99 \\
70 & 39.77 & 29.67 & 11.82 \\
75 & 16.28 & 31.79 & 12.64 \\
80 & 6.67 & 33.91 & 13.45 \\
85 & 2.73 & 36.03 & 14.25 \\
90 & 1.12 & 38.15 & 15.07 \\
\hline
\end{tabular}

The time-dependent behavior of the soil parameter ( $c$ and $\phi$ ) can be drawn as in Figure 9.
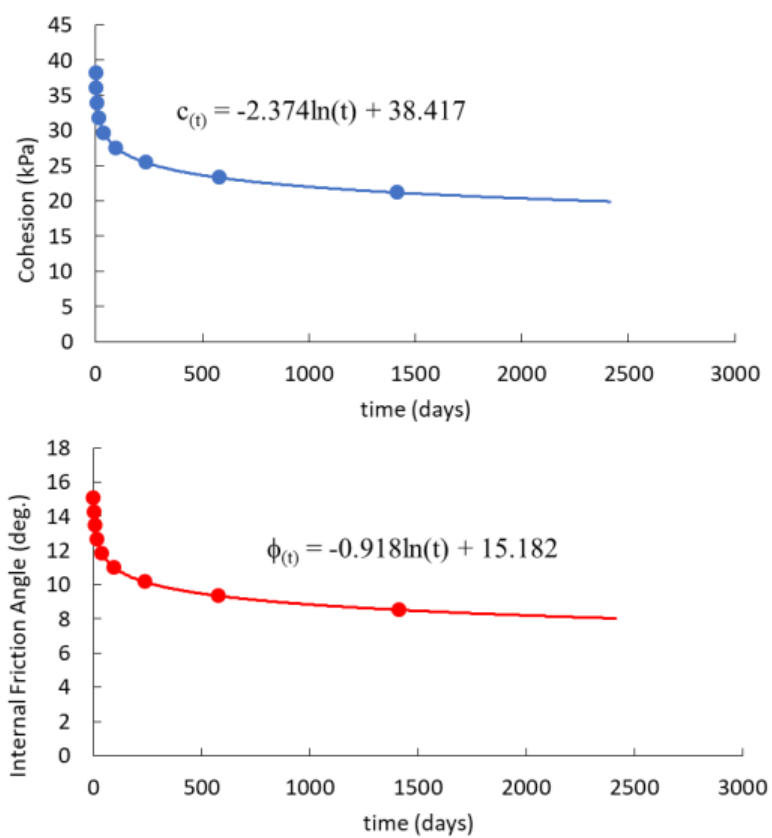

Figure 9 Cohesion (c) and Internal Friction Angle ( $\phi)$ vs time The values of $c$ and $\phi$ in relation with time are represented in Equation (7) and Equation (8):

$c_{(t)}=-2.374 \ln (t)+38.417$

$\phi_{(t)}=-0.918 \ln (t)+15.182$

Based on Figure 9, Equation (7) and Equation (8), it can be concluded that the constant stress has a significant effect on the time-dependent behavior of soil parameters (c and $\phi$ ).

\subsection{CONCLUSION}

Laboratory shear creep tests were carried out on 15 undisturbed soil samples to determine the rheological characteristics of these soils in relation to their longterm strength and time dependent behavior. The shear creep test shows that there are two types of creep curves caused by the applied shear stress level, namely: non-attenuating creep and attenuating creep depend on the shear stress level applied. This proves that the level of constant shear stress applied during the shear creep test will affect to the rheological characteristics of the soil samples. The higher level of shear stress, the shorter failure time.

Rheological modeling shows that the long-term shear strength of Cililin Volcanic Clay decreased up to $52.38 \%$ from its peak shear strength after 925 days ( \pm 31 months). The cohesion (c) and internal friction angle (f) decrease from $41.548 \mathrm{kPa}$ and $17.051^{\circ}$ become $21.188 \mathrm{kPa}$ and $9.129 \circ$. This shows that constant stress has significant effects on the longterm strength of the soil mass.

Rheological modeling also shows that soil parameters (c and f) decrease with time. So, it can be concluded that the constant stress has a significant effect on time-dependent behavior of soil parameters ( $c$ and $\phi)$.

\section{Acknowledgement}

The authors would like to thank the Faculty of Geological Engineering, Padjadjaran University for the opportunity given to the authors.

\section{References}

[1] Zakaria, Z. 2010. Starlet Model, A Proposal for Landslide Disaster Mitigation with a Regional Genetic Approach (Case Study: Landslide at Citatah, Padalarang, West Java). Indonesian Journal on Geosciences. 5(2): 93-112. DOI: https://doi.org/10.17014/ijog.v5i2.95.

[2] Highland, L. W. and Bobrowski, P. T. 2008. The Landslide Handbook - A Guide to Understanding Landslides. US Geological Survey. DOI: https://doi.org/10.3133/cir1325

[3] Tran, T. T. T., Hazarika, H., Indrawan, I. G. B. and Karnawati, D. 2018. Prediction of Time to Soil Failure Based on Creep Strength Reduction Approach. Geotech Geol Eng. 36: 2749-2760.

DOI: https://doi.org/10.1007/s10706-018-0496-9.

[4] Jaeger, J. C., Cook, N. G. W. and Zimmerman, R. W. 2007. Fundamentals of Rock Mechanics. Fourth Edition. Blackwell Publishing, Malden USA. 475.

[5] Yang, W., Duan, K., Zang, Q., Jiao Y. and Wang, S. 2019. In-situ Creep Test on the Long-term Shear Behaviors of a Fault Located at the Dam Foundation of Dagangshan Hydropower Station, China. Energy, Science and Engineering.1-20.

DOI: https://doi.org/10.1002/ese3.521.

[6] Lorig, L. 1999. Lesson Learned from Slope Stability Studies, FLAC and Numerical Modeling in Geomechanics. Detournay \& Hart (eds). Balkema Roterdam.17-21. 
DOI: https://doi.org/10.1201/9781003078531-4.

[7] Baskari, T. L. 2008. Study of Rock Mass Classification on Slope Stability and Determination of Its Long-term Strength in PT. Berau Coal East Kalimantan. Magister Thesis at Dept. of Mining Engineering, Faculty of Mining and Petroleum Engineering, Bandung Institute of Technology.

[8] Luo, Q. and Chen, X. 2014. Experimental Research on Creep Characteristic of Nasha Soft Soil. Hindawi Publishing Corporation the Scientific World Journal.1-8. DOI: https://doi.org/10.1155/2014/968738.,

[9] Fan, Z., Zhang, J. and Yuan H. 2014. A Constitutive Model for Mudstone Shear Creep. EJGE. 19: 259-271.

[10] Wang, D., Qiuling, L. and He, X. 2014. Experiment Study on Rheological Model of Soft Clay. Civil Engineering Journal 8: 344-350. DOI: https://doi.org/10.2174/1874149501408010344.

[11] Ma, C., Zan, H., Yao, W. and Li, H. 2018. A New Shear Rheological Model for a Soft Interlayer with Varying Water Content. Water Science and Engineering. 11 (2): 131-135. DOI: https://doi.org/10.1016/j.wse.2018.07.003.

[12] Liu, H., Li, L., Li, S. and Yang W. 2020. The Time Dependent Failure Mechanism of Rock and Associated Application in Slope Engineering: An Explanation Based on Numerical Investigation. Hindawi Mathematical Problem in Engineering. 20: 1-19.

DOI: https://doi.org/10.1155/2020/1680265.

[13] Saito, M. and Uezawa, H. 1961. Failure of Soil Due to Creep, Railway Technical Research Institute. Japanese National Railways. 315-318.

[14] Fukuzono, T. 1985. A Method to Predict the Time of Slope Failure Caused by Rainfall Using the Inverse Number of Velocity of Surface Displacement. Journal of Japan Landslide Society. 22(2): 8-13.

DOI: https://doi.org/10.3313/jls1964.22.2_8.

[15] Adriansyah, Y. 2013. Predict Time of Failure Based on Slope Movement Monitoring Data at Batu Hijau Open Pit Mine. Proceeding of Geomechanics II Seminar. 145-149.

[16] Li, C., Tang, H., Wang, Y. 2020. Study on Deformation Mechanism of Reservoir Landslides Considering Rheological Properties of the Slip Zone Soil: A Case Study on the Three Gorges Reservoir Region. MDPI Journal Sustainability. 12: 6427 DOI: https://doi.org/10.3390/su1216647.

[17] Centre of Volcanology and Geological Hazard Mitigation. 2017. Map of Vulnerability of Land Movement of West Bandung Regency. Geological Agency of the Ministry of Energy and Mineral Resources, Indonesia.
[18] Vyalov, S. S., Gorodetskii, S. E., Ermakov, V. F., Zatsarnaya, A. G. and Pekarskaya N. K. 1969. Method of Determining Creep, Long-term Strength and Compressibility Characteristic of Frozen Soils. Canada: NRC Publication Archive.1-109.

[19] Vyalov, S. S. 1986. Rheology Fundamentals of Soil Mechanics. Amsterdam: Elsivier.

[20] Schowalter, W. R. 1978. Mechanics of Non-Newtonian Fluids. Pergamon.

[21] Goodman, R. E. 1989. Introductions to Rock Mechanics. $2^{\text {nd }}$ Edition. John Willey \& Sons New York. DOI: https://doi.org/10.4224/20386669.

[22] Andrade, E. N. C. 1910. On the Viscous Flow in Metals and Allied Phenomena. Proceeding of the Royal Society London. 1-12. DOI: https://doi.org/10.1098/rspa.1910.0050.

[23] Andrade, E. N. C. 1962. The Validity of $\mathrm{t}^{1 / 3}$ Law of Flow of Metals. The Philosophical Magazine: A Journal of Theoretical Experimental and Applied Physics. London. 7: 2003-2014. DOI: https://doi.org/10.1080/14786436208214469.

[24] Sudjatmiko. 1972. Geological Map of Cianjur Quadrangle, West Java Scale 1:250.000. Geological Research and Development Centre, Bandung.

[25] Darana, A. R., Jihadi, L. H., Muslim, D., Wahyudi, D. R. and Kristiyanto, T. H. W. 2015. Slope and Lithological Control on Landslide Potential in Mukapayung and Surrounding Area, Cililin District, Bandung Barat Region, West Java, Indonesia. Proceedings International Conference HanoGeo Hanoi. 229-237.

[26] Kurniawan, E. A., Tohari, A. and Permanajati, I. 2018. Lansdlide Susceptibility Model of Cililin District Using TRIGRS. Riset Geologi Pertambangan. 28(2): 167-180. DOI: https://doi.org/10.14203/risetgeotam2018.v28.969.

[27] Skempton, A. W. and Northey, R. D. 1952. The Sensitivity of Clays. Geotechnique. 30-53. DOI: https://doi.org/10.1680/geot.1952.3.1.30.

[28] Mills, P. R. 2016. Static Failure Mechanism in Sensitive Volcanic Clay in the Taurangga Region, New Zealand. MSC Thesis at University of Waikato New Zealand.

[29] Goldstein, M. and Ter-Stepanian, G. 1957. The Long-term Strength of Clays and Depth Creep of Slopes. Proceeding, International Conference of Soil Mechanics and Foundation Engineering $4^{\text {th }} .120-124$. 